\title{
Comparison of interleukin 17 and 22 in saliva of oral lichen planus patients with healthy people
}

\author{
Shiva Shirazian ${ }^{1}$, Farzaneh Aghahosseini², Eisa Salehi ${ }^{3}$, Mehdi Vatanpour ${ }^{4}$, \\ Seyede Niloofar Banijamali ${ }^{5}$ and Sara Pourshahidi ${ }^{*}$ \\ ${ }^{1}$ Assistant Professor, Department of Oral Medicine, School of Dentistry, Tehran University of Medical \\ Sciences, Tehran, Iran \\ ${ }^{2}$ Full Professor, Department of Oral Medicine, School of Dentistry, Tehran University of Medical Sciences, \\ Tehran, Iran \\ ${ }^{3}$ Assistant Professor, Department of Immunology and Biology, School of Medicine, Tehran University of \\ Medical Sciences, Tehran, Iran \\ ${ }^{4}$ Assistant Professor, Department of Endodontics, Dental Branch, Islamic Azad University, Tehran, Iran \\ ${ }^{5}$ Resident of Pediatric Dentistry, Dental Branch, Islamic Azad University, Tehran, Iran \\ ${ }^{6}$ Associated Professor, Department of Oral Medicine, School of Dentistry, Tehran University of Medical \\ Sciences, Tehran, Iran
}

\begin{abstract}
Lichen Planus (LP) is an inflammatory chronic mucocutaneous disease. Since the etiology of OLP is unknown, efforts to understand the etiology and pathogenecity may lead to improve treatment modalities. Studies have shown the different levels of increase or decrease of various cytokines in saliva, serum or tissue culture of patients with OLP.As saliva originates from blood and its collection is an easy, non-invasive method, so it can be a diagnostic fluid that has logistical advantages when compared with serum. The purpose of this study was to compare the salivary level of IL17 and IL22 in patients with and without OLP. Saliva of 52 patients with and without OLP was collected. The saliva level of IL17 and IL 22 was measured by using ELISA. Data were analyzed using independent T test, Mann-Whitney and Pearson Correlation test.The saliva concentration of IL 22 was significantly higher in control group than OLP but the difference was not significant between reticular and atrophic-erosive type (P > 0.05).The difference between mean rank of IL17 for OLP and healthy cases and between reticular and erosive-atrophic form was not significant $(\mathrm{P}>0.05)$. There was no correlation between the level of IL17 and IL $22(\mathrm{P}>0.05)$. Our findings suggest that IL 22 may have an effect in the pathogenesis of OLP and its protective effect may be decreased in OLP patients.
\end{abstract}

KEY WORDS: INTERLEUKIN 17, INTERLEUKIN 22, ORAL LICHEN PLANUS, SALIVA

\section{ARTICLE INFORMATION:}

${ }^{*}$ Corresponding Author: sarapourshahidi20@hotmail.com Received $21^{\text {st }}$ July, 2017

Accepted after revision $29^{\text {th }}$ Sep, 2017

BBRC Print ISSN: 0974-6455

Online ISSN: 2321-4007 CODEN: USA BBRCBA

Thomson Reuters ISI ESC and Crossref Indexed Journal - NAAS Journal Score 2017: 4.31 Cosmos IF: 4.006

- A Society of Science and Nature Publication, 2017. All rights reserved.

Online Contents Available at: http//www.bbrc.in/

DOI: $10.21786 / \mathrm{bbrc} / 10.3 / 37$ 


\section{INTRODUCTION}

Lichen Planus (LP) is an inflammatory chronic mucocutaneous disease that affects 1-2\% of the general population, and is the non-infected mucosal disease causing the most referral to dental clinics (Pakfetrat et al. 2009). The oral cavity is the most common site of the disease. Oral Lichen Planus (OLP) usually affects middle aged women (30-60 years), children are rarely affected.World Health Organization (WHO) has considered OLP as a pre-cancerous disorder. Although OLP is considered an immunologically mediated disease, its etiology is not known, yet. The involvement of both specific and non-specific antigens are considered to have roles in pathogenesis of OLP (van der Meij et al. 2003 Aghahosseini et al. 2006; Pourshahidi et al. 2011; Agha-Hosseini et al. 2015).

Alteration of the immune condition is not well known in OLP to date, but it is clear that cytokines exhibit immunoregulatory actions through a complex cytokine network consisting of paracrine and autocrine systems. Unbalanced cytokine actions are considered to play a role in the pathogenesis of autoimmune diseases. Numerous cytokines are secreted from oral mucosa or blood as locally or systemically that they have an important role in initiation and progression (courses) of OLP (Zhang et al. 2008).

Increased production of cytokine by keratinocytes that may be the result of stimulation by external stimulants is the initial event. Then infiltration of monocytes followed by lymphocytes could be the next step. Studies have shown the different levels of increase or decrease of various cytokines in saliva or serum or tissue culture of patients with OLP (Yamamoto et al. 1990; Rhodus et al. 2005; Zhang et al. 2008).

Interleukin (IL) $17 \mathrm{~A}$, also named IL17, is the most important IL from the IL17 family which is composed of 6 members (IL17A-IL17F). IL 22 is a member of IL10 family and it has a role in immune reaction against bacterial pathogens, especially in epithelium. IL17 and 22 are produced by $\mathrm{T}$ helper 17 and contribute in both innate and acquired immune responses against extra cellular pathogens (Lambiase et al. 2009). The role of Th17 and its cytokines (IL17 and 22) have been established in inflamed tissues in various autoimmune diseases such as psoriasis, multiple sclerosis, lupus erythematosus, rheumatoid arthritis, inflammatory bowel disease (IBD) and pemphigus (Miossec et al. 2009).Saliva originates from blood. Saliva collection is an easy, noninvasive method, and it has been shown that various tumor markers are present in saliva. Therefore it can be a diagnostic fluid that has logistical advantages when compared with serum (Agha-Hosseini et al. 2015). The purpose of this study was to compare the level of IL17 and IL22 in saliva in patients with and without OLP.

\section{MATERIAL AND METHODS}

Fifty two samples of referred patients to the Department of Oral Medicine, Faculty of Dentistry, Tehran University of Medical Sciences included in this cross-sectional study (26 in each group).this study was approved by ethical committee and also all subjects provided written informed consent to participate in the study. OLP was diagnosed clinically and confirmed histopathologically according to the modified WHO criteria in 2003 as below:Clinical criteria: presence of symmetric or bilateral reticular or papular lesions with or without erosiveatrophic components. Histological criteria: presence of well-defined band-like zones of inflammatory infiltration confined to the superficial part of connective tissue, consisting mainly of mature lymphocytes; signs of "liquefaction degeneration" in basal cell layer, absence of epithelial dysplasia. Exclusion criteria: application of any local treatment for OLP lesions during the previous month; taking any drugs during the previous 3 months; history of allergy to foods or environmental factors, smoking; the existence of any oral lesions except OLP, systemic diseases (cardiovascular disease, kidney, hypertension), pregnancy. We also excluded patients whose lesion was nearby amalgam restorations. The unstimulated whole saliva (UWS) was collected between 10:00 a.m. and 12:00 p.m., and at least 90 minutes after the last intake of drink or food. All subjects were requested to swallow first, tilt the head forward and then expectorate at least 5cc UWS into a sterile centrifugal tube without swallowing. The samples were centrifuged (2000g for $10 \mathrm{~min}$ ), and the supernatants stored at -20 oC until analysis. The saliva level of IL was measured by using Enzyme-Linked Immunosorbent Assay (ELISA) kits, Human platiniumIL17A (BMS2017) and Human plutonium IL22 (88-7522-22) (bioscience, USA).

\section{STATISTICAL ANALYSIS}

Independent $\mathrm{T}$ test was used to compare the mean of IL22 between two groups; and Mann-Whitney for IL17. Pearson Correlation test was used for assessing the correlation between IL 17 and IL22 in each group. A P value less than 0.05 was considered statistically significant and primary power of analysis was set at $80 \%$.

\section{RESULTS AND DISCUSSION}

26 patients with OLP (22 females and 4 males) and 26 sex and aged matched healthy individuals were enrolled in this study. The mean age was $50.81 \pm 12.61$ years, and $49.42 \pm 5.33$ years in OLP and control groups respectively. 23\% (6 patients) of OLP was reticular form, and 77\% (20 patients) was atrophic-erosive form. The mean 
of IL22 was $184.48 \pm 4.58 \mathrm{pg} / \mathrm{ml}$ in OLP and $209.01 \pm 4.58$ $\mathrm{pg} / \mathrm{ml}$ in control group, there was significant difference between two groups ( $\mathrm{p}=0.003)$. The mean of IL 22 was $176.5 \pm 9.40 \mathrm{pg} / \mathrm{ml}$ in reticular and $186.88 \pm 5.26$ in atrophic-erosive type but the difference was not significant $(\mathrm{p}=0.35)$.

The mean of IL 17 was $5.24 \pm 2.709 \mathrm{pg} / \mathrm{ml}$ in OLP and $0.526 \pm 0.164 \mathrm{pg} / \mathrm{ml}$ in control. The mean rank of IL17 was 37.33 and 33.59 for OLP and healthy cases respectively. The difference was not significant ( $p=0.436)$. The difference between the mean of IL17 in reticular and erosive-atrophic form was not significant ( $p=0.25)$.

There was no correlation between the level of IL17 and IL22 ( $p=0.35, r=-0.19)$ in healthy patients. Although correlation analysis revealed no significant correlation between IL17 and IL 22 in OLP group but it seems to be a reverse correlation between them according to the statistical findings ( $p=0.054, r=-0.049$ ).

As the etiology of OLP is unknown and because it is one of the most common lesion referred to dental clinics, studies on the pathogenesis of the OLP are of high importance. In this study we evaluated the relevance of IL17 and IL22 with OLP. The saliva concentration of Interleukin 22 was significantly higher in control group than OLP but the difference was not significant between reticular and atrophic- erosive type $(P>0.05)$. We couldn't find any studies on OLP patients' salivary levels of IL22. But Chen et al and Shen et al studied on IL22 in the tissue samples from OLP patients and found it more than their control group (Chen et al. 2011; Shen et al. 2012). More expression of IL22 in the tissue may be due to the location of its receptors which is on the epithelial origin cells (Ouyang et al. 2008). On the other hand there are some researches on the role of IL22 and psoriasis (Zheng et al. 2007; Lowes et al. 2008). Zaba et al. (2007) in an animal study reported the higher expression of IL17 and IL22 in skin lesions of mice with psoriasis; but Zheng and Ma reported that deficiency and limitation of IL22 can exaggerate skin lesion of psoriasis in mice (Zaba et al. 2007; Zheng et al. 2007; Ma et al. 2008). This controversy reveals that more studies should be done on the subject. The salivary level of IL17 in OLP patients of our study was higher than the control group but the difference was not statistically significant $(p=0.436)$. On the basis of our knowledge there is no study on salivary level of IL17 in OLP.

Zhang et al. (2007) compared the level of IL1, IL8 and TNF $\alpha$ in serum and saliva in 30 OLP patients and 30 healthy controls. These IL were higher significantly in saliva and serum in patients than control, and the level of IL8 was higher in saliva in erosive OLP than other types (Zhang et al. 2008). Xie et al. (2012) assessed Th1 and Th17 in tissue (by double immunofluorescence staining) and in serum (by flow cytometry) of 40 patients with OLP (22 cases with reticular type and 18 cases with erosive- atrophic type). Their results showed that the Th17 and Th1 cells were similar in tissue, but both were increased in serum. Th17 was higher in erosive- atrophic OLP than reticular. The level of IL 17 was significantly higher in serum of OLP patients than controls and in erosive-atrophic OLP than reticular.

The role of IL17 has been assessed in other autoimmune diseases in previous studies (Moseley et al. 2003; Nistala et al. 2009; Caproni et al. 2009). Caporni and et al. (2009) evaluated the level of IL17 in serum of psoriasis patients before and after treatment, and compared with healthy controls. The level of IL17 was higher in patients than control and was reduced to a low level after treatment [21]. Ziolkowska et al measured the level of IL17 in serum and synovial fluid of joints in 15 patients with rheumatoid arthritis, and compared with healthy controls. Their results showed higher level of IL17 in patients than control (Ziolkowska et al. 2000). Zhao et al studied the role of Th17 in asthma sensitivity. Percentages of Th17 cells and the level of several cytokines including IL4, IL22, IL25, IL17 and INFy were measured. Th17 cells and related cytokines had the most increasing; additionally, the amount of IL17 and IL22 and Th17 had a positive correlation with the severity of disease (Zhao et al. 2010).

A hypersensitivity reaction is considered in pathogenesis of OLP when cytokines are released by activated $\mathrm{T}$ cell, resulting in accumulation of inflammatory cells, and the destruction of keratinocytes due to the cytotoxicity of cells (Sezer et al. 2007).

The immune mechanism with specific and non specific antigen are proposed in the pathogenesis of OLP (Sugerman et al. 2005). IL17 may up regulate various cytokines like IL1, IL8 and TNF $\alpha$ (Hwang et al. 2004). In the study of Zhang et al (2008) the serum and salivary level of these cytokines was elevated in OLP patients such as other studies (Sun et al. 2005; Rhodus et al. 2006; Janardhanam et al. 2007; Rhodus et al. 2007). Therefore, it may be postulated that IL17 probably has a role in pathogenesis of OLP by increasing these inflammatory cytokines. In non specific antigen, another mechanism may be degranulation of mast cells and activation of MMP (Sugerman et al. 2005). Jovanovic et al (2001) reported that IL17 acts as an up regulator of local inflammatory factors, causing injury of extracellular matrix through MMP (in vitro). Therefore it may be an influence in pathogenesis of OLP. In present study the level of IL17 was ten times higher than the level of healthy control $(5.24 \mathrm{pg} / \mathrm{ml}$ in patients and $0.516 \mathrm{pg} /$ $\mathrm{ml}$ in healthy subjects), although the difference was not significant statistically.

It is clear that IL22 has protection effects while IL 17 has not (Zenewicz et al. 2007; Sonnenberg et al. 2010). Consequently, with the lower level of IL22 and higher 
level of other inflammatory cytokines, epithelial cells are disposed to destroy, and OLP lesions can appear. This hypothesis of the reverse correlation between IL17 and IL22 in patients with OLP is strengthened, but it needs more research.

\section{CONCLUSION}

Our findings suggest that IL 22 may have an effect in the pathogenesis of OLP and its protective effect may be decreased in OLP patients.

\section{ACKNOWLEDGEMENT}

This research has been supported by Tehran University of Medical Sciences \& health Services, Faculty of Dentistry grant91-01-69-16665.

\section{REFERENCES}

Agha-Hosseini F, Mirzaii-Dizgah I, Mahboobi N, Shirazian S, Harirchi I. (2015) Serum and Saliva MMP-3 in Patients with OLP and Oral SCC. J Contemp Dent Pract. 1; 16(2):107-11.

Aghahosseini F, rbabi-Kalati F, Fashtami LA, Fateh M, Djavid GE. (2006) Treatment of oral lichen planus with photodynamic therapy mediated methylene blue: a case report. Med Oral Patol Oral Cir Bucal. (2):E126-E129.

Caproni M, Antiga E, Melani L, Volpi W, Del BE, Fabbri P. (2009) Serum levels of IL-17 and IL-22 are reduced by etanercept, but not by acitretin, in patients with psoriasis: a randomized-controlled trial. J Clin Immunol. 29(2):210-214.

Chen J, Feng J, Chen X,et al. (2013) Immunoexpression of Interleukin-22 and Interleukin-23 in Oral and Cutaneous Lichen Planus Lesions: A Preliminary Study. Mediators Inflamm 801974. doi: 10.1155/2013/801974. Hwang SY, Kim JY, Kim KW, Park MK, Moon Y, Kim WU,Kim YH. (2004) IL-17 induces production of IL- 6 and IL-8 in rheumatoid arthritis synovial fibroblasts via NF-kappaB-and PI3-kinase/Akt-dependent pathways. Arthritis Res Ther . 6(2):120-128.

Janardhanam SB, Prakasam S, Swaminathan VT, Kodumudi KN, Zunt SL, Srinivasan M. (2012) Differential expression of TLR-2 and TLR-4 in the epithelial cells in oral lichen planus. Arch Oral Biol. 57(5):495-502.

Jovanovic DV, Di Battista JA, Martel-Pelletier J, Reboul P, He YULA, Jolicoeur FC, Pelletier JP. (2001) Modulation of TIMP-1 synthesis by antiinflammatory cytokines and prostaglandin E2 in interleukin 17 stimulated human monocytes/macrophages.J Rheumatol. 28(4):712-718.

Lambiase A, Micera A, Mantelli F, et al. (2009) T-helper 17 lymphocytes in ocular cicatricial pemphigoid. Mol Vis. 15:1449-1455.

Lowes MA, Kikuchi T, Fuentes-Duculan J, et al. (2008) Psoriasis vulgaris lesions contain discrete populations of Th1 and Th17 T cells. J Inv Dermatol. 128(5):1207-1211.
Ma HL, Liang S, Li J, et al. (2008) IL-22 is required for Th17 cell-mediated pathology in a mouse model of psoriasis-like skin inflammation. J Clin Invest. 118(2):597-607.

Miossec P, Korn T, Kuchroo VK. (2009) Interleukin-17 and type 17 helper T cells. N Engl J Med . 361(9):888-898.

Moseley TA, Haudenschild DR, Rose L, Reddi AH. (2003) Interleukin-17 family and IL-17 receptors. Cytokine Growth Factor Rev. 14(2):155-174.

Nistala K, Wedderburn LR. (2009) Th17 and regulatory T cells: rebalancing pro-and anti-inflammatory forces in autoimmune arthritis. Rheumatology 48(6):602-606.

Ouyang W, Kolls JK, Zheng Y. (2008) The biological functions of T helper 17 cell effector cytokines in inflammation. Immunity . 28(4):454-467.

Pakfetrat A, Javadzadeh-Bolouri A, Basir-Shabestari S, Falaki F. (2009) Oral Lichen Planus: a retrospective study of 420 Iranian patients. Med Oral Patol Oral Cir Bucal . 14(7):E315-E318.

Pourshahidi S, Ebrahimi H, Andisheh Tadbir A. (2011) Evaluation of the Relationship between Oral Lichen Planus and Stress. Shiraz Univ Dent J 12(1): 43-47.

Rhodus NL, Cheng B, Bowles W, Myers S, Miller L, Ondrey F. (2006) Proinflammatory cytokine levels in saliva before and after treatment of (erosive) oral lichen planus with dexamethasone. Oral Dis. 12(2):112-116.

Rhodus NL, Cheng B, Myers S, Bowles W, Ho V, Ondrey F. (2005) A comparison of the pro-inflammatory, NF-kappaBdependent cytokines: TNF-alpha, IL-1-alpha, IL-6, and IL-8 in different oral fluids from oral lichen planus patients. Clin Immunol. 114(3):278-283.

Rhodus NL, Cheng B, Ondrey F. (2007) Th1/Th2 cytokine ratio in tissue transudates from patients with oral lichen planus. Mediators Inflamm. 19854.

Sezer E, Ozugurlu F, Ozyurt H, Sahin S, Etikan I. (2007) Lipid peroxidation and antioxidant status in lichen planus. Clin Exp Dermatol . 32(4):430-434.

Shen Zh, Du G, Zhou Z, Liu W, Shi L, Xu H. (2016) Aberrant expression of interleukin-22 and its targeting microRNAs in oral lichen planus: a preliminary study.J Oral Pathol Med 45(7):523-527.

Sonnenberg GF, Nair MG, Kirn TJ, Zaph C, Fouser LA, Artis D. (2010) Pathological versus protective functions of IL-22 in airway inflammation are regulated by IL-17A. J Exp Med. 207(6):1293-1305.

Sugerman PB, Savage NW, Walsh LJ, Zhao ZZ, Zhou XJ, Khan A, Seymour GJ, Bigby M. (2002) The pathogenesis of oral lichen planus. Crit Rev Oral Biol Med. 213(4):350-365.

Sun A , Wang JT, Chia JS, Chiang CP. (2005) Serum interleukin-8 level is a more sensitive marker than serum interleukin-6 level in monitoring the disease activity of oral lichen planus. Br J Dermatol. 152(6):1187-1192.

van der Meij EH, van der Waal. (2003) Lack of clinicopathologic correlation in the diagnosis of oral lichen planus based on the presently available diagnostic criteria and suggestions for modifications. J Oral Pathol Med. 32(9):507-512. 
Xie S, Ding L, Xiong Z, Zhu S. (2012) Implications of Th1 and Th17 cells in pathogenesis of oral lichen planus. J Huazhong Univ Sci Technolog Med Sci. 32(3):451-457.

Yamamoto T, Yoneda K, Ueta E, Osaki T. (1990) Cellular immunosuppression in oral lichen planus. J Oral Pathol Med. 19(10):464-470.

Zaba LC, Cardinale I, Gilleaudeau P, et al. (2007) Amelioration of epidermal hyperplasia by TNF inhibition is associated with reduced Th17 responses. J Exp Med. 204(13):3183-3194.

Zenewicz LA, Yancopoulos GD, Valenzuela DM, Murphy AJ, Karow M, Flavell RA. (2007) Interleukin-22 but not interleukin-17 provides protection to hepatocytes during acute liver inflammation. Immunity. 27(4):647-659.

Zhang Y, Lin M, Zhang S, et al. (2008) NF-kappaB-dependent cytokines in saliva and serum from patients with oral lichen planus: a study in an ethnic Chinese population. Cytokine. 41(2):144-149.

Zhao Y, Yang J, Gao Yd, Guo W. (2010) Th17 immunity in patients with allergic asthma. Int Arch Allergy Immunol. 151(4):297-307.

Zheng Y, Danilenko DM, Valdez P, Kasman I, Eastham-Anderson J, Wu J, Ouyang W. (2007) Interleukin-22, a TH17 cytokine, mediates IL-23-induced dermal inflammation and acanthosis. Nature. 445(7128):648-651.

Ziolkowska M, Koc A, Luszczykiewicz G, KsiezopolskaPietrzak K, Klimczak E, Chwalinska-Sadowska H, Maslinski W. (2000) High levels of IL-17 in rheumatoid arthritis patients: IL-15 triggers in vitro IL-17 production via cyclosporin A-sensitive mechanism. J Immunol . 164(5):28322838. 